IJPSR (2011), Vol. 2, Issue 4

(Review Article)

INTERNATIONAL JOURNAL
OHARMACEUTICAL SCIENCES
PEESEARCH

Received on 21 October, 2010; received in revised form 23 January, 2011; accepted 03 March, 2011

\title{
PHYTOMEDICINES AND COGNITION
}

\author{
A. V. Pattewar* ${ }^{1}$, R. G. Katedeshmukh ${ }^{2}$, N. S. Vyawahare ${ }^{3}$, V. G. Kagathara ${ }^{4}$ \\ SVNHT's College of Pharmacy ${ }^{1}$, Rahuri, Maharashtra, India \\ Indira College of Pharmacy ${ }^{2}$, Pune, Maharashtra, India \\ AISSMS College of Pharmacy ${ }^{3}$, Pune-387001, Maharashtra, India \\ Faculty of Pharmacy, Dharmsinh Desai University ${ }^{4}$, Nadiad, Gujarat, India
}

\begin{abstract}
Keywords:

Alternative system of medicine, cognition,

learning, memory

Correspondence to Author:

A. V. Pattewar

SVNHT's College of Pharmacy, Rahuri, Maharashtra, India

Email:

pharma_cology24@yahoo.co.in

Learning is the process of acquisition of information and skills, while subsequent retention of that information is called memory. Learning and memory together called as cognition. Also, memory is a process involving encoding, storing, and recalling information. Thus, memory records various facts and events, make it available for further use, and hence can be considered as most valuable health asset. To elucidate the biochemical and molecular mechanisms underlying learning and memory could be considered as one of the challenging tasks for neuroscientists. Poor memory, lower retention, and slow recall are common problems in today's stressful and competitive world, especially with associated ageing process. Furthermore, the drugs currently available in market for the treatment of various learning and memory disorders are associated with several side effects indicating need of substitute medication from alternative system of medicine. On the other hand, several medicinal plants, designated as "Rasayan Drugs" in Ayurveda, are supposed to have specific influence on brain functions, and could be effectively used to treat such disorders without the associated side effects. In light of this, the present review encompasses the brief descriptive information about various herbal drugs used in the alternative system of medicine to treat the diseases related to cognition with the view to aid the further research to prepare an ideal medicine for its use in learning and memory processes.
\end{abstract}

Available online on www.ijpsr.com

778 
INTRODUCTION: Memory is the ability of an individual to record sensory stimuli, events, information etc., retain them over a short or long period of time and recall the same at a later date when needed ${ }^{1}$. Learning is the process of acquiring knowledge about the world and memory could be considered as the retention of the acquired knowledge, which can be retrieved as and when, required 2. Poor learning abilities, impaired memory, lower retention and slow recall are the common problems in stressful situations. Moreover, age, stress and emotions are conditions that may lead to impaired learning, memory loss, amnesia, and dementia or to more ominous threats like Schizophrenia and Alzheimer's disease ${ }^{3}$.

Memory function is vulnerable to a variety of pathologic processes including neurodegenerative diseases, strokes, tumors, head trauma, hypoxia, cardiac surgery, malnutrition, attention-deficit disorder, depression, anxiety and the side effects of medication, and normal ageing ${ }^{4}$. Learning and memory are generated by an experience dependent and long-lasting modification of the central nervous system. They involve activation by neurotransmitters, such as, acetylcholine, dopamine, and serotonin, of the receptor-linked enzymes that are responsible for the synthesis of intercellular messengers.

A large number of studies have shown that the cholinergic system plays an important role in learning and memory. Moreover, a loss of cholinergic neurons and reduced cholineacetyltransferase activity in the cerebral cortex and hippocampus are consistent with findings in Alzheimer's disease (AD) ${ }^{5}$. In fact, reduced cholinergic activity in the brains of individuals with $A D$ provides the rationale for the development of acetyl cholinesterase (AChE) inhibitors to treat the dementia associated with AD. The commonly prescribed AChE inhibitors, such as Donepezil, Rivastigmine, and Galantamine were developed on this basis ${ }^{5}$. As memory involves many interwoven brain functions, there are several different types of memories and virtually any type of brain damage can result in one or other type of memory loss ${ }^{6}$.

In recent years, efforts have been made to find new therapeutic agents for the prevention or treatment of memory disorders, such as the gradual impairment of memory in aging or in neurodegenerative pathology and even lifestyle factors, but an effective therapy for the resolution of the cognitive deficits is still needed. Moreover drugs that could not only treat but also prevent diseases of older adults are needed in the clinical practice. Both prevention and delay of these disorder onsets would have a large impact in terms of reducing both suffering and costs ${ }^{7}$.

Through the ages, many medicinal herbs have been used to improve memory and cognitive function and to treat neurodegenerative diseases in traditional medicine ${ }^{8}$. Pharmacological effects of some plants have also been reported ${ }^{9}$. Ayurveda, the Indian system of medicine, is gaining greater attention and popularity in many parts of the world. The disease preventive and health promotive approach of ayurveda, which takes into consideration the whole body, mind and spirit while dealing with the maintenance of health promotions, now enjoys increasing acceptability ${ }^{10}$.

Ayurveda had developed certain dietary and therapeutic measures to delay ageing and rejuvenating whole functional dynamics of the body organs. This revitalization and rejuvenation is known as the 'Rasayana chikitsa' (rejuvenation therapy) ${ }^{10}$. Ayurveda claims that several plants, called as the "Medhya" plants (intellect promoting) herbs are beneficial in cognitive disorders ${ }^{11}$. The scientific documentation for the research progress of some of the herbal drugs (Phytomedicines) that have been used in alternative system for treatment 
of disorders related to learning and memory is presented below.

Scientific documentation of herbs: Zingiber officinale Roscoe is commonly known as ginger and used as a 'rasayana' drug in the traditional system of medicine since time immemorial. Topic et al., ${ }^{12}$ reported the enhancement of the learning process by the ginger using morris water maze test while the extract inhibited the $\beta$-amyloid peptideaccumulation, reflecting its usefulness in delaying the onset and progression of neurodegenerative disorders ${ }^{13}$. Joshi and Parle ${ }^{11}$ evaluated the nootropic effect of different doses (50 and 100 $\mathrm{mg} / \mathrm{kg}$, p.o.) of Zingiber officinale extract employing elevated plus maze and passive avoidance paradigm. They administered $Z$. officinale extract (50 and $100 \mathrm{mg} / \mathrm{kg}$, p.o.) for 8 successive days to both young and aged mice.

The dose of $100 \mathrm{mg} / \mathrm{kg}$ of $Z$. officinale extract significantly improved learning and memory in young mice and also reversed the amnesia induced by diazepam (1mg/kg, i.p.), and scopolamine $(0.4 \mathrm{mg} / \mathrm{kg}$, i.p.). Furthermore, it also reversed aging induced amnesia of mice. $Z$. officinale significantly increased whole brain acetyl cholinesterase inhibition activity providing the evidence for its use as memory restorative agent in the treatment of dementia seen in the elderly. The underlying mechanism of its action may be attributed to its antioxidant and acetyl cholinesterase inhibition property ${ }^{11}$.

Bacopa monniera, a member of the scrophulariaceae family, is a small, creeping herb with numerous branches, small oblong leaves, and light purple flowers ${ }^{14}$. It has been used in ayurvedic medicine and in traditional treatments for a number of disorders, particularly those involving anxiety, intellect, and poor memory ${ }^{15}$. The plant has prominent action on the central nervous system, where it improves understanding, memory, intellect, and speech, and corrects aberrations of emotions, mood, and personality in an individual. Vollala et al., ${ }^{16}$ examined the effect of Bacopa monniera Linn. (brahmi) extract (20, 40 and $80 \mathrm{mg} / \mathrm{kg}$ ) on learning and memory in rats employing spatial learning (T-maze) and passive avoidance tests.

The results showed improvement in spatial learning performance and enhanced memory retention in rats treated with extract. The probable mechanism was attributed to its action on the repair of damaged neurons, neuronal synthesis, and the restoration of synaptic activity with ultimately effect on nerve impulse transmission ${ }^{16}$. In another study investigated by Saraf et al., ${ }^{17}$, Bacopa monniera significantly alleviated $\mathrm{N} \omega$-nitroL-arginine methyl ester (L-NAME) (a nitric oxide inhibitor) induced amnesia in mouse model of morris water maze study. Nitric oxide synthase (NOS) mediated pathway was supposed to plays a more dominant role in $B$. monniera-mediated reversal of amnesia ${ }^{17}$.

In Ayurveda, Ocimum sanctum Linn. (Lamiaceae) popularly known as the sacred tulsi (holy basil) and has been in clinical use for centuries $^{18}$. Nootropic potential of aqueous extract of Ocimum sanctum Linn $(50,100$ and $200 \mathrm{mg} / \mathrm{kg}$, po) in mice was evaluated by Joshi and Parle ${ }^{18}$ using elevated plus maze and passive avoidance paradigms as an exteroceptive behavioral models. The extract significantly ameliorated the amnesic effect of scopolamine $(0.4 \mathrm{mg} / \mathrm{kg})$, diazepam $(1 \mathrm{mg} / \mathrm{kg})$ and ageing induced memory deficit in mice. Also, the extract decreased the transfer latency and increased step down latency when compared to control (piracetam treated), scopolamine and aged groups of mice significantly suggesting its beneficial use in the treatment of cognitive disorders such as dementia and Alzheimers disease. The probable mechanism of nootropic activity was attributed to its anti- 
inflammatory, antioxidant, antistress and neuroprotective effects ${ }^{18}$. Lepidium meyenii Walp. (Brassicaceae), known as Maca, is a Peruvian plant growing exclusively between 4000 and $4500 \mathrm{~m}$ altitude in the central Peruvian Andes, particularly in Junin plateau ${ }^{19}$. Rubio et al., ${ }^{19}$ evaluated the effect of two different doses of aqueous ( 0.50 ans $2.00 \mathrm{~g} / \mathrm{kg})$ and hydroalcoholic $(0.50$ and $1.00 \mathrm{~g} / \mathrm{kg})$ extracts of Black Maca on male mice with memory impairment induced by scopolamine using the water

Morris maze and the step-down avoidance test. In addition, the brain activities of AChE and Mono amine oxidase (MAO) were assessed. Both extracts of Black Maca significantly ameliorated the scopolamine-induced memory impairment as measured in both the water Morris maze and the step-down avoidance tests. Black Maca extracts inhibited AChE activity, whereas MAO activity was not affected. These results indicate that Black Maca improves scopolamine-induced memory deficits. Effect of Black Maca on learning and memory may be due to the presence of polyphenolic compounds such as quercetin and anthocyanins on Black Maca hypocotyls ${ }^{19}$.

Cognitive enhancement effect of hydroalcoholic extract of stems from Equisetum arvense L. (HAE) was evaluated in aged rats after chronic administration by Santos Junior et al., ${ }^{20}$. Chronic administration of HAE at dose of $50 \mathrm{mg} / \mathrm{kg}$, i.p., improved both short- and long-term retention of inhibitory avoidance task and ameliorated the cognitive performance in reference and working memory version of the Morris Water Maze. No differences were found between all three groups of young controls, aged controls and EHA-treated animals with regard to the open field and elevated plus maze tests. Indeed, no toxicity manifestations were observed during treatment. In vitro assays revealed that $\mathrm{HAE}$ diminished the thiobarbituric acid reactive substances as well as nitrite formation, but did not alter catalase activity. Thus, the cognitive enhancement effects of the HAE may be attributed, at least in part, to it antioxidant action $^{20}$.

Effect of a polyphenol-rich wild blueberry extract $(\mathrm{PrB})$ (Vaccinium angustifolium) on cognitive performance of mice, brain antioxidant markers and acetylcholinesterase activity was investigated by Papandreou et al., ${ }^{21}$. Results showed that the $\operatorname{PrB} 60 \mathrm{mg} / \mathrm{kg}$ - treated mice exhibited a significant improvement in learning and memory. PrB extract administration also resulted in reduced lipid peroxidation products and higher brain ascorbic acid levels in both PrB $30 \mathrm{mg} / \mathrm{kg}$ and PrB $60 \mathrm{mg} / \mathrm{kg}$-treated groups, respectively, and higher glutathione levels (28\%) in the PrB $60 \mathrm{mg} / \mathrm{kg}$ treated group. Furthermore, salt- and detergent soluble AChE activity significantly decreased in both PrB-treated groups.

Thus, they observed the significant cognitive enhancement in adult mice after shortterm i.p. supplementation with the blueberry extract concentrated in polyphenols, which is closely related to higher brain antioxidant properties and inhibition of AChE activity. These findings stress the critical impact of wild blueberry bioactive components on brain function ${ }^{21}$. Agerelated damage starts accumulating substantially once development of the body is complete and then it starts undergoing degenerative changes showing signs of old age.

Many brain modifications have been described in aging viz. cognitive functions, learning ability and memory retention which decline very frequently with age ${ }^{22}$. Effects of green tea extract on learning, memory, behavior and acetylcholinesterase activity in young and old male rats was studied by Kaur et al., ${ }^{23}$. Thet administered young and old rats orally with $0.5 \%$ green tea extract for a period of eight weeks and 
then evaluated by passive avoidance, elevated maze plus paradigm and changes in acetylcholinesterase activity. Green tea extracts significantly improved learning and memory in older rats, with increased retention latency to enter difference in passive avoidance test. In the elevated maze test, green tea treatment resulted in significantly more number of entries in the enclosed arm by the young and old rats. Decline in acetylcholinesterase activity was observed in the cerebrum of green tea treated old rats in comparison to the green tea treated young rats. These results suggested the use of green tea in reversing age-related deficits ${ }^{23}$, but the mechanism was unclear.

Adaptogenic and nootropic activities of aqueous extract of Vitis vinifera (grape seed) (100, 200 and $300 \mathrm{mg} / \mathrm{kg}$ ) was evaluated by Sreemantula et al., ${ }^{24}$ in a rat model of scopolamine induced amnesia in conditioned avoidance response using Cook's pole climbing apparatus. The cognition, as determined by the acquisition, retention and recovery in rats was observed to be dose dependent. They correlated the anti-stress and antioxidant activities with the nootropic activity of the extract since the role of stress and free radicals have been implicated in the loss of memory, concentration and also in Alzheimer's disease ${ }^{25,26}$. They attributed the nootropic activity to central cholinomimetic activity apart from its free radical scavenging mechanisms ${ }^{24}$.

Vyawahare et al., ${ }^{27}$ evaluated the the different doses $(300$ and $500 \mathrm{mg} / \mathrm{kg}$ ) of alcoholic extract of roots of Clitoria ternatea for its antiamnesic activity against scopolamine induced amnesia in rats using passive avoidance and step down type of passive avoidance task model. The results revealed that dose of $500 \mathrm{mg} / \mathrm{kg}$ was more effective as it prevented the scopolamine induced memory loss in both passive avoidance and step down type of passive avoidance task model.
Biochemical study revealed that antiamnestic activity was probably associated with reduction in acetylcholinesterase (AChE) activity which reduces the destruction of neurotransmitter, acetylcholine (ACh), in the brain ${ }^{27}$. Furthermore, in their another study ${ }^{28}$, they have reported the significant memory retention property of Clitoria ternatea against electroshock induced amnesia in rats and the probable mechanism was attributed to increase in $\mathrm{ACh}$ content of whole brain and decrease in AChE activity in different regions of the brain compared to respective controls qualitatively 28.

Bramhi Ghrita (BG) is one of the polyherbal formulations mentioned in Ayurveda (an Indian system of medicine) containing Bacopa monneri (8 g), Acorus calamus (4 g), Evolvulus alsinoids (4 g), Saussurea lappa (4 g) and cow's ghee (80 g). This formulation has been used traditionally as a memory enhancer and for its anticonvulsant activity ${ }^{29}$. Achliya et al.., ${ }^{30}$ tested the effect of BG (30, 50 and $100 \mathrm{mg} / \mathrm{kg}$, p.o.) on learning and memory processes. The activity of BG on memory acquisition and retention was studied using elevated plus maze model (EPM) in rats, and on spatial memory using Morris water maze model (MWM) in mice.

In the result, the administration of Bramhi Ghrita (50 and $100 \mathrm{mg} / \mathrm{kg}$, p.o.) showed significant reduction in transfer latency in EPM and escape latency in MWM as compared with the control group. They have concluded the use of BG as a memory enhancer formulation and may also be useful as a supportive adjuvant in the treatment of impaired memory functions. The plant Bacopa monneri is a well-known nootropic plant and a proven memory enhancer agent. Bacosides are the main active nootropic principle present in the alcoholic extract of the plant. Apart from memory enhancer activity these bacosides have the potential to modulate the activities of heat stock 
protein (HSP70) expression, cytochrome $\mathrm{P}_{450}$ and superoxide dismutase in the rat brain ${ }^{31}$. Dementia is a syndrome of failing memory and other intellectual functions with little or no disturbance in consciousness. Degeneration of the cerebral neurons is one of the commonest and vital causes for dementia with increasing age, there by leading to deterioration in quality of life in elderly ${ }^{32}$. Tinospora cordifolia has been extensively studied and reported to have potent immuno-stimulant action ${ }^{33-35}$. In addition Tinospora cordifolia also found to have anti-stress ${ }^{36}$ effects. Ayurvedic literature recommends a rejuvenating recipe where Tinospora cordifolia being an important constituent to enhance the memory function ${ }^{37}$. However, there is no experimental evidence to support memory enhancing property of Tinospora cordifolia.

Agarwal et al., ${ }^{38}$ studied the effect of Tinospora cordifolia (Tc) on learning and memory in normal and cyclosporine induced memory deficit rats. There are reports that administration of cyclosporine in chicks produced cognitive deficits 39. Similar cognitive impairment was also observed in patients following cyclosporine administration ${ }^{40}$. They administered the alcoholic and aqueous extracts of the whole plant of Tinospora cordifolia orally for 15 days in two groups of rats. Cyclosporine $15,25 \mathrm{mg} / \mathrm{kg}$, i.p. was administered on alternate days for 10 days.

Combination of cyclosporine $25 \mathrm{mg} / \mathrm{kg}$, i.p. for 10 days and Tc alcoholic $200 \mathrm{mg} / \mathrm{kg}$ and Tc aqueous $100 \mathrm{mg} / \mathrm{kg}$ were administered in two different groups of rats. At the end of treatment, they assessed learning and memory using Hebb William maze and passive avoidance task. Both alcoholic and aqueous extracts of Tc produced a decrease in learning scores in Hebb William maze and retention memory indicating enhancement of learning and memory. However, cyclosporine at both the doses increased the learning scores in
Hebb William maze and decrease in retention time in the passive avoidance task suggesting a memory deficit. The combination of cyclosporine and Tc produced a decrease in learning scores in Hebb William maze and increase latency in passive avoidance task compared to cyclosporine alone treated rats. The probable mechanism of cognitive enhancement by Tc could be by immunostimulation and increasing the synthesis of acetylcholine which is an important neurotransmitter in learning and memory process. This central action could be due to supplementation of choline which is an important active constituent of Tc. Also, there are reports that supplementation of choline enhances the cognitive function in animals ${ }^{38}$.

Ziziphus mauritiana Lam. (FamilyRhamnaceae) is an important tropical fruit tree that contains important source of compounds (flavonoids, glycosides, saponins and volatile oil) with a wide profile of putative therapeutical applications ${ }^{41}$. The roots of Ziziphus species are commonly used in folklore medicine for the treatment of diarrhea, digestive disorders, weakness, liver complaints, obesity, urinary troubles, skin infections, loss of appetite, fever, bronchitis, convulsion, epilepsy, insomnia and are known for their anxiolytic and sedative properties 42,43

Substances with sedatives properties have been shown to play crucial role in many types of learning and memory ${ }^{44,45}$ and may cause cognitive and emotional impairments. Sadiq et al., ${ }^{46}$ studied the influence of acute administration of ethyl acetate, ethanol and aqueous seed extracts of $Z$. mauritiana on spatial recognition memory in Wistar rats using the Y-maze. Spatial memory was measured by the total number of entries and duration spent in each arm of the Y-maze following administration of the extracts intraperitoneally. Transfer latency ( $T L$ ) in the $Y$ maze was expressed 
as inflexion ratio (IR). The number of arm visits during the first trial and second trial period were measured as an index of locomotor activity. Scopolamine $(0.4 \mathrm{mg} / \mathrm{kg})$ was used to induce amnesia in the animals. The results indicated that, after $24 \mathrm{~h}, \mathrm{IR}$ was slightly increased ( $P>0.05)$ by ethanol and aqueous extracts while ethyl acetate extract significantly reduced the IR $(P<0.05)$ compared to controls.

All doses of ethyl acetate extract impaired spatial recognition memory after a $24 \mathrm{~h}$ trial interval, whereas aqueous and ethanol extracts did not showed this impairment. All the extracts significantly decreased locomotor activity of the animals $(P<0.001)$. None of the extracts reversed scopolamine induced amnesia in the rats. These data suggested that seed extracts of $Z$. mauritiana impaired spatial recognition memory and decreased locomotor activity of rodents, the activity of which was greatly produced by the portion extracted by ethyl acetate ${ }^{[46]}$. The extract was supposed to act by its putative mechanisms of action.

Mangos are a source of bioactive compounds with potential health-promoting activity. Kumar et al., ${ }^{47}$ evaluated the effect of ethanolic extract of Mangifera indica L. fruit on cognitive performances. The models used to study the effect on cognitive performances were step down passive avoidance task and elevated plus maze task in mice. Chronic treatment (7 days) of extract and vitamin C significantly $(p<0.05)$ reversed the aging and scopolamine induced memory deficits in both paradigms. Preliminary phytochemical screening revealed the presence of free sugars, saponins, tannins, and flavonoids. The results suggested that the extract contained pharmacologically active principles that are memory-enhancing in nature. They attributed the antiamnestic activity of the extract to its antioxidant activity ${ }^{47}$.
Mitragyna speciosa Korth from Rubiaceae family is a tropical plant indigenous to Southeast Asia particularly in Thailand, Peninsular of Malaysia and Indonesia. The leaves have been used by natives for their opium-like effect and cocaine-like stimulant ability to combat fatigue and enhance tolerance to hard work ${ }^{48}$. Apryani et al., ${ }^{48}$ investigated the working memory effects of mitragynine which is extracted from Mitragyna speciosa mature leaves. They studied the cognitive effect using object location task and the motor activity in open-field test. Mitragynine 5, 10 and 15 $\mathrm{mg} / \mathrm{kg}$ and were administered by intraperitoneal (IP) for 28 consecutive days and evaluated on day 28 after the last dose treatment.

Scopolamine was used as the control positive drug. In the result of object location task, mitragynine $(5,10$ and $15 \mathrm{mg} / \mathrm{kg}$ ) did not showed any significances discrimination between the object that had changed position than the object that had remain in a constant position. Results suggesed that chronic administration of mitragynine can alter the cognitive behavioral function in mice by the unknown mechanism ${ }^{48}$. Although normal cognitive changes take place when a person becomes older, aging in humans is generally associated with deterioration of cognitive performance and, in particular, of learning and memory. These cognitive deficits can cause debilitating consequences due to aging.

There are a number of herbal medicines which are reported to improve brain function including intelligence ${ }^{49}$. Zhang et al.., ${ }^{49}$ evaluated the improving effects of tenuifolin, extracted from Radix Polygalae (RP), on learning and memory in aged and dysmnesia mice using step-down type passive avoidance test or $Y$ type maze trial. Oral administration of tenuifolin $(0.02,0.04,0.08 \mathrm{~g} / \mathrm{kg}$ per day, for $15 \mathrm{~d}$ ) evidently improved the latency and number of errors in aged and dysmnesia mice. The levels of cortical acetylcholine esterase (AChE) 
activity and hippocampal neurotransmitters in aged mice given tenuifolin $(0.02,0.04,0.08 \mathrm{~g} / \mathrm{kg}$ per day, for $15 \mathrm{~d}$ ) were also investigated, and increased levels of norepinephrine (NE), dopamine (DA), decreased activity of AChE were found. However, serotonin (5-HT) had no significant difference from that of aged mice given distilled water. The evident improvement of learning and memory of aged mice was carried out by the effects of tenuifolin on the three stages of memory process, that is, acquisition, consolidation and retrieval. These actions might be due to increasing the levels of NE, DA in the hippocampus and by decreasing the activity of AChE in the cortex ${ }^{49}$.

Kang et al., ${ }^{50}$ assessed the effects of oral treatments of ESP-102, a standardized combined extract of Angelica gigas, Saururus chinensis and Schizandra chinensis, on learning and memory deficit. The cognition-enhancing effect of ESP-102 was investigated in scopolamine-induced $(1 \mathrm{mg} / \mathrm{kg}$ body weight, s.c.) amnesic mice with both passive avoidance and Morris water maze performance tests. Acute oral treatment (single administration prior to scopolamine treatment) of mice with ESP102 (doses in the range of 10 to $100 \mathrm{mg} / \mathrm{kg}$ body weight) significantly reduced scopolamine-induced memory deficits in the passive avoidance performance test.

Another noteworthy result included the fact that prolonged oral daily treatments of mice with much lower amounts of ESP-102 (1 and 10mg/kg body weight) for ten days reversed scopolamineinduced memory deficits. In the Morris water maze performance test, both acute and prolonged oral treatments with ESP-102 single administration of $100 \mathrm{mg} / \mathrm{kg}$ body weight or prolonged daily administration of 1 and $10 \mathrm{mg} / \mathrm{kg}$ body weight for ten days, respectively, significantly ameliorated scopolamine-induced memory deficits as indicated by the formation of long-term and/or short-term spatial memory ${ }^{50}$.
Phyllanthus amarus Linn. (PA) is an annual weed of the family of the Euphorbiaceae commonly known as bhumi amla in India and is traditionally used to treat flu, dropsy, diabetes, and jaundice. Joshi et al. [51] investigated the effects of Phyllanhus amarus (PA) on cognitive functions and brain cholinesterase activity in mice. Elevated plus maze and passive avoidance paradigm were employed to evaluate learning and memory parameters. They administered three doses (50, 100 and $200 \mathrm{mg} / \mathrm{kg}$, p.o.) of aqueous extract of PA for 8 successive days to both young and aged mice. PA (50, 100 and 200 $\mathrm{mg} / \mathrm{kg}$ ) produced a dose-dependent improvement in memory scores of young and older mice.

PA also reversed successfully the amnesia induced by scopolamine $(0.4 \mathrm{mg} / \mathrm{kg}$, i.p.) and diazepam ( $1 \mathrm{mg} / \mathrm{kg}$, i.p.). Interestingly, brain acetyl cholinesterase activity was also reduced. The underlying mechanism of action for the observed nootropic effect may be attributed to procholinergic activity exhibited by PA. They reported the therapeutic potential of PA in the management of patients with cognitive disorders ${ }^{51}$. Gomisin $A$ is a component of the fruits of Schizandra chinesis which are widely used as a tonic in traditional Chinese medicine. Kim et al., ${ }^{52}$ assessed the effect of gomisin A on the learning and memory impairments induced by scopolamine. The cognition-enhancing effect of gomisin $A$ was investigated using a passive avoidance test, the $\mathrm{Y}$ maze test, and the Morris water maze test in mice.

Drug-induced amnesia was induced by treating animals with scopolamine $(1 \mathrm{mg} / \mathrm{kg}$, i.p.). Gomisin A $(5 \mathrm{mg} / \mathrm{kg}$, p.o.) administration significantly reversed scopolamine induced cognitive impairments in mice by the passive avoidance test and the $\mathrm{Y}$-maze test $(\mathrm{P}<0.05)$, and also improved escape latency in the Morris water maze test at $5 \mathrm{mg} / \mathrm{kg}(\mathrm{P}<0.05)$. Moreover, in an in vitro study, gomisin A was found to inhibit acetylcholinesterase activity in a dose dependent 
manner. These results suggested that gomisin $A$ could be a useful cognitive impairment treatment, and its beneficial effects are mediated, in part, via enhancing the cholinergic nervous system ${ }^{52}$.

The fruit Emblica officinalis Gaertn., syn: Phyllanthus emblica (Euphorbiaceae), Emblic myrobalan locally known as Amla or Amlaj is one of the important herbal drugs used in Unani (GraecoArab) and Ayurvedic systems of medicine ${ }^{53}$. Emblica officinalis (E. officinalis) is used both as a medicine and as a tonic to build up lost vitality and vigor. According to the two main classic texts on Ayurved, Charaka Samhita and Sushruta Samhita, Amalaki is regarded as "the best among rejuvenative herbs", "useful in relieving cough and skin disease" and "the best among the sour fruits" 54. E. officinalis is a major ingredient in several important medicinal preparations including Triphala ("three fruits") and the famous Chyawanprash, a general tonic for people of all ages, which improves mental and physical well being ${ }^{55,56}$.

Vasudevan and Parle ${ }^{57}$ evaluated the effects of Anwala churna (Emblica officinalis Gaertn.), an Ayurvedic preparation on memory, total serum cholesterol levels and brain cholinesterase activity in mice. They administered Anwala churna orally in three doses $(50,100$ and $200 \mathrm{mg} / \mathrm{kg}$ ) for fifteen days to different groups of young and aged mice. Elevated plus maze and passive avoidance apparatus served as the exteroceptive behavioral models for testing memory. Diazepam, scopolamine and ageinginduced amnesia served as the interoceptive behavioral models. Total serum cholesterol levels and brain cholinesterase activity also estimated. Anwala churna (50, 100 and $200 \mathrm{mg} / \mathrm{kg}$, p.o.) produced a dose-dependent improvement in memory scores of young and aged mice. Furthermore, it reversed the amnesia induced by scopolamine $(0.4 \mathrm{mg} / \mathrm{kg}$, i.p.) and diazepam
$(1 \mathrm{mg} / \mathrm{kg}$, i.p.). Interestingly, brain cholinesterase activity and total cholesterol levels were reduced by Anwala churna administered orally for 15 days. Anwala churna may prove to be a useful remedy for the management of Alzheimer's disease on account of its multifarious beneficial effects such as, memory improving property, cholesterol lowering property and anticholinesterase activity 57

In the traditional system of medicine, the roots and rhizomes of Glycyrrhiza glabra (family: Leguminosae) have been employed clinically for centuries for their anti-inflammatory, antiulcer, expectorant, antimicrobial and anxiolytic activities 58. Dhingra et al., ${ }^{58}$ investigated the effects of Glycyrrhiza glabra (popularly known as liquorice) on learning and memory in mice. Elevated plusmaze and passive avoidance paradigm were employed to test learning and memory. They administered three doses $(75,150$ and $300 \mathrm{mg} / \mathrm{kg}$ p.o.) of aqueous extract of Glycyrrhiza glabra for 7 successive days in separate groups of animals. The dose of $150 \mathrm{mg} / \mathrm{kg}$ of the aqueous extract of liquorice significantly improved learning and memory of mice.

Furthermore, this dose significantly reversed the amnesia induced by diazepam $(1 \mathrm{mg} / \mathrm{kg}$ i.p.) and scopolamine $(0.4 \mathrm{mg} / \mathrm{kg}$ i.p.). Antiinflammatory and antioxidant properties of liquorice might be contributed favorably to the memory enhancement effect. Since scopolamineinduced amnesia was reversed by liquorice, could be possible that the beneficial effect on learning and memory was due to facilitation of cholinergictransmission in mouse brain ${ }^{58}$. The effect of saponin containing $n$-butanolic fraction (BF) extracted from dried leaves of Albizzia lebbeck on learning and memory was studied Chintawar et al. [59] in albino mice using passive shock avoidance paradigm and the elevated plus maze. Significant improvement was observed in the retention ability 
of the normal and amnesic mice as compared to their respective controls. They have also studied the effects of BF on the behavior influenced by serotonin (5-HT), noradrenaline and dopamine. The brain levels of serotonin, gamma-aminobutyric acid (GABA) and dopamine were also estimated to correlate the behavior with neurotransmitter levels. The brain concentrations of GABA and dopamine were decreased, whereas the 5-HT level was increased. The data indicated the involvement of monoamine neurotransmitters in the nootropic action of BF of $A$. lebbeck ${ }^{59}$.

Hibiscus sabdariffa Linn. (Malvaceae) is commonly known as red sorrel in English, Lal lambari in hindi, pundibija in kannada and the dried calyx is used as a diuretic, sedative, refrigerant ${ }^{60}$ and for making a drink by boiling in water and adding a little salt, pepper, asafetida and molasses to treat mental fatigue due to excessive heating by the Gondas tribal of Karnataka, India. It is native of tropical Africa or Asia and is now found widely cultivated throughout tropics of India. The tender leaves and stalks are eaten as salad, as curries and an infusion of the calyces are used as laxative, in cardiovascular and nervous diseases ${ }^{61}$. $H$. sabdariffa reported to be antiseptic, aphrodisiac, astringent, resolvent, cholagogue, digestive, diuretic and stomachic ${ }^{62}$. Hibiscus tea has been shown to lower blood pressure in patients with essential hypertension ${ }^{63}$.

A polyherbal drug, Anna Pavala Sindhooram (Sidha formulation) contains flowers of $H$. sabdariffa as major constituents and is used in the management of atherosclerosis. Calyces are used in West Indies to color and flavor rum, Seeds are used for preparing an aphrodisiac herbal tea, and the fruits are edible ${ }^{[64]}$. Nootropic acitivity of calyces of Hibiscus sabdariffa Linn. was studied in mice by Joshi and Parle $\left.{ }^{[65}\right]$. Elevated plus maze and passive avoidance paradigm were employed to evaluate learning and memory parameters.
Scopolamine $(0.4 \mathrm{mg} / \mathrm{kg}$, i.p.) was used to induce amnesia in mice. The aqueous extracts of calyces of Hibiscus sabdariffa (HS-100 and $200 \mathrm{mg} / \mathrm{kg}$, p.o.) significantly attenuated amnestic deficits induced by scopolamine $(0.4 \mathrm{mg} / \mathrm{kg}$, i.p.) and natural aging. HS (100 and $200 \mathrm{mg} / \mathrm{kg}$ ) decreased the transfer latencies and increased step down latencies significantly in the aged mice and scopolamine induced amnesic mice as compared with Piracetam (200 mg/kg, i.p.). To delineate the possible mechanism through which $H$. sabdariffa elicits the anti-amnesic effects, they studied its influence on central cholinergic activity by estimating the whole brain acetylcholinesterase activity. H. sabdariffa significantly decreased acetylcholinesterase activity in mice.

The results indicated that, the aqueous extract of calyces of $H$. sabdariffa might prove to be a useful memory restorative agent in the treatment of dementia seen in elderly. The underlying mechanism of action can be attributed to its anti acetylcholinesterase property ${ }^{65}$. Desmodium gangeticum DC. (Leguminosae) is commonly known as Shalparni in Sanskrit. It is abundantly found throughout India. It is one of the important plants used in indigenous system of medicine as a bitter tonic, febrifuge, digestive, and antiemitic in inflammatory conditions which are due to vata disorder ${ }^{66}$.

It is used in 'Ayurvedic' preparations like 'Dashmoolarishta' and 'Dashmoolakwaath'and for treatment of nervous disorders ${ }^{67}$. Joshi and Parle [68] investigated the effectiveness of aqueous extract of $D$. gangeticum in attenuating scopolamine-induced amnesia in mice. Passive avoidance paradigm was used to assess long-term memory. In order to delineate the possible mechanism through which $D$. gangeticum elicits the anti-amnesic effects, they studied its influence on central cholinergic activity by estimating the acetylcholine content of the whole brain and 
acetylcholinesterase activity at different regions of the mouse brain, viz., cerebral cortex, midbrain, medulla oblongata and cerebellum. Pretreatment with $D$. gangeticum $(100 \mathrm{mg} / \mathrm{kg}$ and $200 \mathrm{mg} / \mathrm{kg}$, p.o.) for seven successive days, reversed scopolamine induced amnesia in mice. D. gangeticum increased mice brain acetylcholine content and decreased acetyl cholinesterase activity in a similar manner to the standard cerebro-protective drug piracetam. Hence, aqueous extract of $D$. gangeticum can be used to delay the onset and reduce the severity of the symptoms of dementia and Alzheimer's disease 68 .

Curcuma longa is a well known medicinal plant with established anticancer, antiinflammatory and neuroprotective effects ${ }^{69}$. Its rhizome contains essential oils (such as turmerones and zingiberene), turmerin (a water-soluble peptide) and curcuminoids which can be defined as phenolic compounds derived from the roots ${ }^{[70]}$. The most important constituent of the standardised extract of dried rhizome of C. longa is curcumin (diferuloylmethane), lowmolecularweight polyphenol generally regarded as the most active constituent ${ }^{71}$. The effects of chronic pre-treatment with a standardised extract of Curcuma longa on learning and spatial memory in aged 24-month old male Wistar rats were estimated in a Morris water maze paradigm Pyrzanowska et al., ${ }^{71}$. They treated the animals with the extract orally for two months in prepared rodent chow to obtain the doses 10 and $50 \mathrm{mg} / \mathrm{kg} /$ day.

At the end of behavioral trials the concentration of neurotransmitters, their metabolites and amino acids in selected brain regions were estimated. They found a significant decrease in escape latency over four days of training in both treated groups in comparison to the control group. In a probe trial on the 5th day the $\mathrm{C} 10$ group crossed the target area more often and spent more time in the SE quadrant than control group. Significant differences in brain monoamines and amino acid levels between groups were noticed. The increase in the 5-HT (5hydroxytryptamine) level in the prefrontal cortex correlated positively with the number of crossings over the target area during the first probe trial in both pre-treated groups. The plasma corticosterone level was lower in both pre-treated groups than in the control group. This suggested enhanced learning ability and spatial memory after C. longa extract treatment with the modulation of central serotoninergic system activity, and may be linked with an increased tolerance to stress conditions.

A decrease in hippocampal glutamate in animals given plant extract compared to control rats was observed. It might be possible that extract may influence a reduction in glutamate-induced excitotoxicity and consequently the neurodegeneration processes in the hippocampus 71. Dried Euphoria longan fruit is prescribed as a tonic and for the treatment of forgetfulness, insomnia, or palpitations caused by fright in traditional Chinese medicine. The effects of aqueous extract of Euphoria longan fruit (ELE) on learning and memory and their underlying mechanisms were investigated by Park et al., ${ }^{72}$. Aqueous extract of Euphoria longan fruit (ELE) was administered to ICR mice for 14 days. Piracetam was used as a positive control for its known memory-enhancing effects.

Memory performances were assessed using the passive avoidance task. The expressions of phosphorylated extracellular signal-regulated kinase (pERK) $1 / 2$, phosphorylated cAMP response element binding protein ( $p C R E B)$, brain-derived neurotrophic factor (BDNF), doublecortin (DCX) and the incorporation of 5-bromo-2-deoxyuridine (BrdU) in hippocampal dentate gyrus and CA1 regions were investigated using 
immunohistochemical methods. The step-through latency in the ELE-treated group was significantly increased compared with that in the vehicletreated controls $(P<0.05)$ in the passive avoidance task. Piracetam-treated group also showed enhanced cognitive performaces in the passive avoidance task.

Immunohistochemical studies revealed that the number of cells immunopositive for BDNF, PCREB, or pERK $1 / 2$ was significantly increased in the hippocampal dentate gyrus and $C A 1$ regions after ELE treatment for 14 days $(P<0.05)$. DCX and BrdU immunostaining also revealed that ELE significantly enhanced immature neuronal survival, but not neuronal cell proliferation in the subgranular zone of the dentate gyrus. The present results suggested that subchronic administration of aqueous extract of Euphoria longan fruit enhances learning and memory, and that its beneficial effects are mediated, in part, by BDNF expression and immature neuronal survival ${ }^{72}$.

CONCLUSION: In traditional system of medicines, various plants and their isolated phytochemicals have been used for treatment of various disorders related to learning and memory. It can be concluded that a variety of plants has great potential to show activities relevant for their use in the disorders like Alzheimers disease and Dementia. In majority of the studies, the underlying mechanism was found to be anti acetylcholinesterase activity and free radical scavenging activity with the facilitation of the cholinergic transmission. Also, many herbal drugs reversed age related disorders with unknown mechanisms. However further studies regarding the role of phytoconstituents and compounds responsible for exact mechanism are necessary in order to develop and ideal agent for the treatment of various learning and memory related disorders. The typical scientific approach for selecting plants to investigate for the treatment of these disorders is relatively rational method to develop more acceptable and better substitute to the present pharmacotherapy.

\section{REFERENCES:}

1. Vasudevan $\mathrm{M}$ and Parle $\mathrm{M}$ : Pharmacological actions of Thespesia populnea relevant to Alzheimers disease. Phytomedicine. 2006; 13: 677-87.

2. Kupfermann I. Learning and Memory, Principles of neural science. Prentice Hall International: London; 1993.

3. Franchis $P$, Palmer $A$, Snape $M$ and Wilcock G: The cholinergic hypothesis of Alzheimers disease: a review of progress. Journal of Neurology Neurosurgery and Psychiatry. 1999; 66: 137-47.

4. Joshi H, Megeri K, Bidchol MA and Kulkarni VH: Clerodendron phlomidis Linn improves short term memory of chemically and naturally induced amnesia in mice. Natural Product. 2007; 3(3): 166-70.

5. Kim DH, Yoon BH, KimYW, Lee S, Bum YS and Jung JW: The Seed Extract of Cassia obtusifolia ameliorates learning and memory impairments induced by scopolamine or transient cerebral hypoperfusion in mice. Journal Pharmacological Sciences. 2007; (105): 82-93.

6. Beers $\mathrm{MH}$. The Merck manual of medical information, $2^{\text {nd }}$ Ed. New Jersey: Merck and Co, INC; 2003.

7. Oliveira DR, Sanada PF, Saragossa FAC, Innocenti LR, Oler Gisele, Cerutti JM et al: Neuromodulatory property of standardized extract Ginkgo biloba L. (EGb 761) on memory: Behavioral and molecular evidence. Brain Research. 2009, 1269: 68-89.

8. Howes MJ and Houghton PJ: Plants used in Chinese and Indian traditional medicine for improvement of memory and cognitive function, Pharmacology Biochemistry Behavior 2003; 75: 513-27.

9. Oh MS, Huh Y, Bae H, Ahn DK and Park SK: The multiherbal formula Guibitang enhances memory and increases cell proliferation in the rat hippocampus, Neurosciene. Lettrs 2005; 379: 205-8.

10. Govindarajan R, Vijayakumar $M$ and Pushpangadan $P$ : Antioxidant approach to disease management and the role of 'Rasayana' herbs of Ayurveda. Journal of Ethnopharmacology 2005; 99: 165-78.

11. Joshi $\mathrm{H}$ and Parle $\mathrm{M}$ : Zingiber officinale: evaulation of its nootropic effect in mice. African Journal of Traditional and CAM. 2006; 3(1): 64-74.

12. Topic B, Tani E, Tsiakitzis K, Kourounakis PN, Dere E, Hasenohrl RU et al: Enhanced maze performance and reduced oxidative stress by combined extracts of Zingiber officinale and Ginkgo biloba in the aged rat: Neurobiology and Aging. 2002; 23: 135-43.

13. Grzanna R, Phan P, Polotsky A, Lindmark L and Frondoza CG: Ginger extract inhibits beta-Amyloid peptide-induced Cytokine and Chemokine expression in cultured THP-1 monocytes: Journal of Alternative and Complementary Medicine 2004; 10: 1009-13. 
14. Warrier PK, Nambiar VPK, Ramankutty C. Indian Medicinal Plants. Orient Longman, Chennai, India. 1996.

15. Singh HK and Dhawan BN: Neuropsychopharmacological effects of the Ayurvedic nootropic Bacopa monniera Linn. (Brahmi). Indian Journal of Pharmacology. 1997; 29: 35965.

16. Vollala VR, Upadhya S and Nayak S: Effect of Bacopa monniera Linn. (brahmi) extract on learning and memory in rats: A behavioral study. Journal of Veterinary Behavior. 2010; 5: 69-74.

17. Saraf MK, Prabhakar S and Anand A: Bacopa monniera alleviates Nw-nitro-L-arginine induced but not MK-801induced amnesia: A mouse morris water maze study. Neuroscience. 2009; 160: 149-55.

18. Joshi $\mathrm{H}$ and Parle M. Evaluation of nootropic potential of Ocimum sanctum Linn in mice. Indian Journal of Experimental Biology. 2006; 44: 133-6.

19. Rubio J, Dang Haixia, Gong Mengjuan, Liu Xinmin, Chen Shi-lin and Gonzales GF: Aqueous and hydroalcoholic extracts of Black Maca (Lepidium meyenii) improve scopolamine-induced memory impairment in mice. Food and Chemical Toxicology. 2007; 45: 1882-90.

20. Santos Junior JG, Martins do Monte FH, Blanco MM, Lanziotti VMNB, Maia FD and Almeida Leal LK: Cognitive enhancement in aged rats after chronic administration of Equisetum arvense $\mathrm{L}$. with demonstrated antioxidant properties in vitro. Pharmacology Biochemistry Behavior. 2005; 81: $593-600$.

21. Papandreou MA, Dimakopoulou A, Linardaki ZI, Cordopatis $P$, Zacas DK, Margarity $M$ et al: Effect of a polyphenol-rich wild blueberry extract on cognitive performance of mice, brain antioxidant markers and acetylcholinesterase activity. Behavioral Brain Research 2009; 198: 352-8.

22. Dmitrieva ES, Gel'man VIA, Zatseva KA and Lan'ko SV: Agerelated changes in the relationship between learning progress and auditory working memory characteristics. Zh Vyssh Nerv Deiat Im I P Pavlova. 2007; 57: 268-75.

23. Kaur T, Pathak CM, Pandhi $P$ and Khanduja KL: Effects of green tea extract on learning, memory, and behavior and acetylcholinesterase activity in young and old male rats. Brain and Cognition. 2008; 67: 25-30.

24. Sreemantula1S, Nammi S, Kolanukonda R, Koppula $S$ and Boini KM: Adaptogenic and nootropic activities of aqueous extract of Vitis vinifera (grape seed): an experimental study in rat model. BMC Complementary Alternative Medicine. 2005; 5:1-8.

25. Esch $\mathrm{T}$, Stefano $\mathrm{GB}$, Fricchione $\mathrm{GL}$ and Benson $\mathrm{H}$ : The role of stress in neurodegenerative diseases and mental disorders. Neuroendocrinology Letters 2002; 23:199-208.

26. Jodar L, Takahashi M and Kaneto H: Effects of footshock-, psychological- and forced swimming-stress on the learning and memory processes: involvement of opioidergic pathways. Japanese Journal of Pharmacology 1995; 67:143-7.

27. Vyawahare NS, Nikam AP, Kamble PN, Bodhankar SL and Khandelwal AR: Evaluation of antiamnestic activity of
Clitoria ternatea against scopolamine induced amnesia in rats. Journal of Cell and Tissue Research 2006; 6 (1): 711-3.

28. Vyawahare NS, Nikam AP, Sharma RG, Deshpande MM, Tarnalli AD and Bodhankar SL: Effect of Clitoria ternatea extract on radial arm maze task performance and central cholinergic activity in rats. Journal of Cell and Tissue Research 2007; 7 (1): 949-52.

29. Tripathi B. Caraka Samhita. 3rd Ed, Vol-II. Chaukhamba Surbharati Prakashan, Vanarasi: 1994.

30. Achliya G, Barabde U, Wadodkar S and Dorle A: Effect of Bramhi Ghrita, an polyherbal formulation on learning and memory paradigms in experimental animals. Indian Journal of Pharmacology. 2004; 36(3 ): 159-62

31. Choudhari DK, Parmar D, Kakkar P, Shukla R, Seth PK and Srimal RC: Antistress effects of bacosides of Bacopa monneri: modulation of $\mathrm{Hsp70}$ expression, superoxide dismutase and cytochrome P450 activity in rat brain. Phytotherapy Research 2002;16: 639-45.

32. Adam, Victor: Dementia and Amnesic syndrome: With comments on neurology of intelligence and memory. I. In: Victor $M$, Ropper AD, editors. Principles of neurology. New York: McGraw Hill; 2001.

33. Thatte UM, Dhanukar SA and Rao SGA: Tinospora induces colony stimulating activity in serum. Journal of Postgraduate Medicine. 1989; 40: 202-3.

34. Thatte UM, Chhabria SN, Karandikar SM and Dhanukar SA: Protective effect of Indian medicinal plants against cyclophosphmide neutropenia. Journal of Postgraduate Medicine 1987; 33:185-8.

35. Usha D, Thatte UM, Joshi DS and Dhanukar SA: Flow cytometric evaluation of bone marrow proliferation induced by Tinospora cordifolia. Update Ayurveda. 1994; 94:38- 42.

36. Khosa RL, Sarma DNK, Ghanasauria JPN and Ray AK: Effect of Tinospora cordifolia on brain neurotransmitter in stressed rats. Fitoterapia 1995; 14i: 421-2.

37. Satyavati G:. Pharmacological Review: Medhya Rasayana. In: Chaudhri RD, ed. Herbal drug industry, $1^{\text {st }}$ edn. New Delhi: Estern Publishers; 1996.

38. Agarwa A, Malini S, Bairy KL and Rao MS: Effect of Tinospora cardifolia on learning and memory in normal and memory deficit rats. Indian Journal of Pharmacology. 2002; 34: 339-49.

39. Bennett PC, Zhao $W$ and Lawen A: Cyclosporine $A$, an inhibitor of calcineurin, impairs memory formation in 10 day old chicks. Brain Research. 1996; 730:107-17.

40. Craven JL: Cyclosporine associated organic mental disorder in liver transplant recepients. Psychosomatic. 1991; 32: 94102.

41. Dahiru, D, Sini JM and John-Africa L: Antidiarrhoeal activity of Ziziphus mauritiana root extract in rodents. African Journal of Biotechnology. 2006; 5(10): 941-5.

42. Msonthi JD, Magombo D and Hamdard: Medicinal Herbs in Malawi and their Uses. Hamdard Medicus. 1983; 26 (2): 94-100.

43. Jiang, JG, Huang XJ, Chen J and Lin QS: Comparison of the sedative and hypnotic effects of flavonoids, saponins, and 
polysaccharides extracted from Semen Ziziphus jujube. Natural Product Research. 2007; 21(4): 310-20.

44. Wezenberg E, Sabbe BG, Hulstjn W, Ruigt GS and Verkes RJ: The role of sedation tests in identifying sedative drug effects in healthy volunteers and their power to dissociate sedative-related impairments from memory dysfunctions. Journal of Psychopharmacology 2007; 21:579.

45. Kaindl AM, Koppelstaetter A, Nebrich G, Stuwe J, Sifringer $M$, Zabel $C$ et al: Brief Alteration of NMDA or GABAA receptor-mediated neurotransmission has long term effects on the developing cerebral cortex. Moleclar Cell Proteomics. 2008; 7: 2293-310.

46. Sadiq $Y$, Alexander $A B$ and Abdulkarim A: Effect of Ziziphus mauritiania (L.) seed extracts on spatial recognition memory of rats as measured by the Y-maze test. Journal of Natural Products. 2009; 2: 31-9.

47. Kumar S, Maheshwari KK and Singh V: Effects of Mangifera indica fruit extract on cognitive deficits in mice. Journal of Environment Biology. 2009; 30(4): 563-6.

48. Apryani E, Hidayat TM, Moklas MAA, Fakurazi S and Idayu NF: Effects of mitragynine from Mitragyna speciosa Korth leaves on working memory. Journal of Ethnopharmacology. 2010; 129: 357-60.

49. Zhang $\mathrm{H}, \mathrm{Han} \mathrm{T}$, Zhang L, Yu CH, Wan DG, Rahman $\mathrm{K}$ et al: Effects of tenuifolin extracted from radix polygalae on learning and memory: A behavioral and biochemical study on aged and amnesic mice. Phytomedicine. 2008; 15: 58794.

50. Kang SY, Lee KY, Koo KA, Yoon JS, Song LW, Kim YC et al: ESP-102, a standardized combined extract of Angelica gigas, Saururus chinensis and Schizandra chinensis, significantly improved scopolamine-induced memory impairment in mice. Life Sciences, 2005; 76: 1691-705.

51. Joshi $\mathrm{H}$ and Parle M: Evaluation of the antiamnesic effects of Phyllanthus amarus in mice. Colombian Medicine. 2007; 38: 132-9.

52. Kim DH, Hung TM, Bae KH, Jung JW, Lee $\mathrm{S}$, Yoon BH et al: Gomisin A improves scopolamine-induced memory impairment in mice. European Journal of Pharmacology. 2006; 542:129-35.

53. Kirtikar KR and Basu BD: Indian Medicinal Plants, Indian edition, vol. 2. Lalit Mohan Basu Publications, Allahabad, India: 1933.

54. Perry LM. Medicinal Plants of East and South East Asia: Attributed Properties and Uses. MIT Press, Cambridge: 1980.

55. Manjunatha S, Jaryal AK, Bijlani RL, Sachdeva U and Gupta SK: Effect of Chyawanprash and vitamin $C$ on glucose tolerance and lipoprotein profile. Indian Journal of Physiology and Pharmacology. 2001; 45:71-9.

56. Nadkarni KM. Dr K.M. Nadkarni's Indian Meteria Medica. The Karnataka printing press and the popular press Ltd, Bombay, India: 1976.
57. Vasudevan $\mathrm{M}$ and Parle M: Memory enhancing activity of Anwala churna (Emblica officinalis Gaertn.): An Ayurvedic preparation. Physiology and Behavior. 2007; 91: 46-54.

58. Dhingra $D$, Parle $M$ and Kulkarni. SK: Memory enhancing activity of Glycyrrhiza glabra in mice. Journal of Ethnopharmacology. 2004; 91: 361-5.

59. Chintawar SD, Somani RS, Kasture VS and Kasture SB: Nootropic activity of Albizzia lebbeck in mice. Journal of Ethnopharmacology 2002; 81: 299-305.

60. Kirtikar KR and Basu BD: Indian Medicinal Plants. Bishen Singh Mahendra pal Singh, Dehradun, 1993.

61. Anonymous. The wealth of India, Raw materials, National Institute of Science Communication, New Delhi, 1997.

62. Perry JM. Medicinal Plants of East and Southeast Asia Attributed Properties and Uses. MIT Press, Cambridge, MA, 1980.

63. Farayi $\mathrm{MH}$ and Tarkhani $\mathrm{AH}$ : The effect of sour tea (Hibiscus sabdariffa) on essential hypertension. Journal of Ethnopharmacology 1999; 7: 231-6.

64. Watt JM and Breyer-Bradndwijk MG: The Medicinal and Poisonous Plants of Southern and Eastern Africa, 2nd ed. E \& S Livingstone, Ltd., Edinburgh and London, 1962.

65. Joshi $\mathrm{H}$ and Parle $\mathrm{M}$ : Nootropic Activity of Calyces of Hibiscus sabdariffa Linn. Iranian Journal of Pharmacology and Therapeutics. 2006; 5 (1): 15-20.

66. Chopra RN, Nayar SL and Chopra IC: Glossary of Indian Medicinal Plants. Council of Scientific and Industrial Research, New Delhi 1954.

67. Prayagadatta S. Sharangadhra Samhita. Chowkhamba Sanskrita Academy, Varanasi 1966.

68. Joshi $\mathrm{H}$ and Parle $\mathrm{M}$ : Pharmacological Evidences for the antiamnesic effects of Desmodium gangeticum in mice. Iranian Journal of Pharmaceutical Research. 2007; 6 (3): 199-207

69. Goel A, Kunnumakkara AB and Aggarwal BB: Curcumin as "Curecumin": from kitchen to clinic. Biochemistry and Pharmacology. 2008; 75: 787-809.

70. Hiserodt R, Hartman TG, Ho CT and Rosen RT: Characterization of powdered turmeric by liquid chromatography-mass spectrometry and gas chromatography-mass spectrometry. Journal of Chromatography 1996; 740: 51-63.

71. Pyrzanowska J, Piechal A, Blecharz-Klin K, Lehner $M$, Skórzewska A, Turzyńska $D$ et al: The influence of the longterm administration of Curcuma longa extract on learning and spatial memory as well as the concentration of brain neurotransmitters and level of plasma corticosterone in aged rats. Pharmacology Biochemistry Behavior 2010; 95: 351-8.

72. Park SJ, Park DH, Kim DH, Lee S, Yoon BH, Jung WY et al; The memory-enhancing effects of Euphoria longan fruit extract in mice. Journal of Ethnopharmacology 2010; 128: $160-5$. 